\title{
Vida de la Academia
}

Durante la Sesión Solemne Estatutaria realizada el miércoles 19 de agosto de 2020 se hizo un homenaje al general Francisco de Paula Santander, a su vida, a su legado y, sobre todo, a su visión sobre la importancia de la educación y la ciencia para el futuro del país.

El profesor Olympo Morales Benítez, Presidente de la Academia Santanderista de Colombia, fue el encargado de la conferencia magistral que transcribimos a continuación.

\section{Francisco de Paula Santander}

Estratega y estadista: de la acción a la reflexión y a la consolidación

Gracias a la Academia Colombiana de Ciencias Exactas, Físicas y Naturales, y muy especialmente al académico santanderista y presidente de esta institución, don Enrique Forero, por abrir este sobrio espacio de reflexión científica para que desde lo institucional se escuche mi voz como Presidente de la Academia Santanderista de Colombia, y así difundir el esfuerzo que muchos hacemos por continuar rescatando sin desfallecer la trascendental gesta política y militar de Francisco de Paula Santander; con el Llano como su génesis, este prohombre se consagró como el "Arquitecto de la Nación" y de sus instituciones, que hoy nos enorgullecen y protegen preservando con su solidez el devenir de la vida democrática y civil de todos los colombianos.

Convocamos en estas bicentenarias fechas la memoria alrededor de la cimera figura militar y civil de Francisco de Paula Santander, estratega de la independencia de Indoamérica, quien ha sido distinguido con el título de Hombre de las Leyes, en el ejercicio de la concepción e implementación de lo que llegaría a ser nuestra democracia representativa republicana. Para construirla establece como prioridad la instrucción de los mestizos espirituales que conformarían las naciones americanas sin distingos de origen, raza, edad, sexo o condición.

\section{Ancestros y primeros años}

Francisco José de Paula Santander y Omaña (Villa del Rosario, 2 de abril de 1792 Bogotá, 6 de mayo de 1840), fue hijo de Juan Agustín Santander y Colmenares -quien fuera gobernador de la Provincia de San Faustino de los Ríos y cultivador en sus posesiones rurales- y de doña Manuela Antonia de Omaña Rivadeneira y Rodríguez, ambos pertenecientes a familias criollas, descendientes de funcionarios coloniales llegados al entonces Nuevo Reino de Granada. Su infancia transcurrió en la comodidad de las haciendas de café, caña de azúcar y cacao que poseía su padre.

Santander y Omaña fue un revolucionario, estratega militar y político, estadista y jurista colombiano. Prócer de la Independencia de Colombia. Participó como protagonista destacado en la Guerra de Independencia. Desempeñó un rol determinante en el cruce de Teatinos (Batalla de Boyacá) y en reconocimiento fue ascendido por Bolívar al rango de General. Fue reconocido como el "Organizador de la Victoria", y nombrado Vicepresidente de la Gran Colombia en el período de 1819-1827 (encargado del poder ejecutivo) y Presidente de la República de la Nueva Granada entre 1832 y 1837.

\section{Su primera escuela}

El hecho de haber estudiado en su niñez y adolescencia en diferentes instituciones sembró en Santander el convencimiento suficiente para barruntar cuál sería su papel en la vida de la inexistente nación, y la educación sería para él herramienta insustituible en la formación de la identidad de una comunidad que terminaría siendo la tan atormentada como pujante y resiliente Colombia. 
Su primera experiencia educacional trascurre en su niñez e infancia, en la hacienda donde nació, ubicada al oriente inmediato de la Villa del Rosario. Sus primeros estudios los realizó en la escuela de doña Bárbara Josefa Chávez, maestra a la "usanza antigua, eternamente ceñuda, severísima con sus discípulos y menos inclinada al estímulo que al castigo".

\section{Superiores etapas educacionales formativas}

Continuó su educación cuando a la edad de doce años fue traído a Santafé en el año de 1805 por su tío el presbítero Nicolás de Omaña Rivadeneira, y allí, apadrinado por quien luego se convertiría en su profesor y más adelante en su jefe, don Custodio García Rovira, entró en el célebre Colegio de San Bartolomé gozando de la beca bartolina que verdaderamente aprovechó pues se distinguió en filosofía, derecho canónico e incluso incursionó en el novedoso derecho de gentes. Casi culminando sus estudios de Derecho en la Universidad Santo Tomás, en el año 1810, lo sorprende el coordinado levantamiento del 20 de Julio que conocemos como el grito de Independencia y que derivaría en la Guerra de Independencia.

\section{Entorno histórico en los inicios de su vida en la milicia}

Apenas terminados sus estudios universitarios, Santander inicia su vida militar el 26 de octubre de 1810, como abanderado del Batallón Guardias Nacionales de Santafé y en ese mismo año lo promueven al grado de subteniente en Mariquita. Regresa a Santafé y es designado ayudante secretario de Antonio Baraya.

Santander se une a los federalistas en 1812. Herido y prisionero por los centralistas en Santafé, es rescatado por su Batallón, el Quinto de la Unión, y con él se dirige a Cúcuta.

En el año 1813, actúa en Bailadores como Jefe de Vanguardia. Bolívar es nombrado Brigadier de los ejércitos de la Unión. México emite su primer grito de independencia, Jean-Baptiste Bernardotte es elegido sucesor de Carlos XIII, rey de Suecia. Insurrección en Cartagena y Buenos Aires. El Congreso Venezolano decreta independencia del país y México finalmente se declara independiente. ${ }^{2}$

\section{Articulación y construcción del grueso del Ejército Libertador}

Tres grupos patriotas independientes entre sí obraban en los Llanos del hoy departamento de Casanare. Una columna era dirigida por el coronel venezolano Miguel Valdés, comandante general de las tropas de Casanare o ejército de oriente, cuyo centro de operaciones principal estaba localizado en Guasdualito. El segundo grupo estaba comandado por el coronel, también casanareño, Nepomuceno Moreno, gobernador de Casanare, y el tercero era aquel que estaba dirigido por el general venezolano Rafael Urdaneta. Santander llega a Casanare y, desde Laguna en el camino de la Victoria cerca de Pore, usa su influencia como "hombre de la pluma", como lo apodaron peyorativamente en esa época y logra unir los tres jefes enfrentados.

\section{Una mujer clave para la subsistencia de la naciente fuerza militar}

La heroica María Rosa Lazo de la Vega, propietaria de la hacienda Tocaría, que se extendía desde el piedemonte de Nunchía e incluía las sabanas de San Luis y parte de las de Pore, confió en el liderazgo de Santander y alimentó y dio refugio a la tropa independentista -se dice que durante más de cuatro años (entre 1815 y 1819)-, en los terrenos de su finca. Son muchas las mujeres que a los estudiosos de la historia nos van apareciendo como protagonistas en la causa de la Independencia. Cuentan los historiadores que la mayoría de los caballos que movilizaron a la tropa hacia les épicas batallas por nuestra libertad fueron propiedad cedida a la causa por esta casanareña.

\footnotetext{
${ }^{1}$ Arias, Juan de Dios. Santander Esquicio Biográfico del Prócer. Bucaramanga: Imprenta del Departamento, 1939, p. 10.

${ }^{2}$ Academia Colombiana de Historia. El libro de oro de Santander. Bogotá: Plaza \& Janés, 1983.
} 


\section{La ruta fluvial hacia la libertad}

Santander aprovecha su conocimiento de la geografía del llano y diseña la ruta fluvial que une a Casanare con el Vichada, y que inicia en Pore y termina en el almacén de acopio de todo género militar en Santa Rosalía. Esta ruta incluye el Cuartel General de la Trinidad y Guanapalo, y conduce desde el cuartel de reposo en el invierno llanero que algunos sitúan alrededor de la Laguna que se encuentra en el camino a la Victoria hasta los ríos de refrescante espuma que con hoy sus históricas aguas serán a la vez obstáculo y apoyo para que las quillas de las barcazas independentistas indoamericanas.

Nuestra nación colombiana fue concebida por seres que desde nuestro trópico llanero soñaron una nación no para caminarla en europeas botas militares, sino para ser reflexionada por los pensadores que, como Santander, avizoraron el futuro que hoy en nuestro presente vivimos. Lo soñaron literalmente encotillados y temporalmente uniformados para combatir por la independencia y posterior consolidación de la democracia concebida en la América Moderna, así como con los derechos humanos que con Jefferson llegaron a Francia y de allí descendieron a la tierra de la libertad para ser traducidos por Nariño. ${ }^{3}$

Repetidas lecciones de generosidady grandeza de dos de los baluartes de la Independencia: Santander y Bolívar

Para nuestro héroe, la hora para la invasión en busca de la libertad de la Nueva Granada había llegado. Santander había soñado en las muchas noches de Laguna con el histórico momento y había insistido por todos los medios a su alcance ante Bolívar para que la acción se llevara a cabo cuanto antes. En su visión, que se probó acertada había calculado que era menester tomar posesión de Santafé, para desde allí irradiar todo el esfuerzo para libertar el continente.

Bolívar contestaba:

Aún no sé positivamente -escribe a Santander-el día, ni me he decidido sobre el modo en que debe ejecutarse; así me limito a indicar a usted el movimiento para que se prepare y a encargarle con el último encarecimiento el secreto, sin el cual nada podrá hacerse. Usted sólo, sólo debe saberlo (Cañafistolo, 20 de mayo de 1819). ${ }^{4}$

Al final, quien llegaría a ser conocido como El Libertador aceptó la sugerencia del estratega Santander y se decidió por la ruta que atraviesa el páramo de Pisba, a pesar de ser más fragosa, despoblada y penosa.

El camino sugerido por Francisco de Paula une a partir de Nunchía las poblaciones de Morcote, Paya y Pisba cruzando el páramo para llegar a Sochaviejo, población ya situada al otro lado de la cordillera en el altiplano boyacense. Bordea el río Payero por su margen izquierda. Esta travesía tenía la ventaja sobre los otros caminos estudiados, de que era la más corta y menos defendida por el enemigo, como se puede deducir de lo escrito por José María Barreiro y fechado el 25 de junio de 1819 en donde en un oficio a Juan Sámano, expresaba:

El paso de la cordillera no lo pueden ejecutar por otros puntos, que por los de Salinas, Paya, Puebloviejo, Miraflores y todo el Valle de Tenza, Medina y Cáqueza. Los pasos de Salinas, Paya, Pueblo viejo y Medina son páramos y montañas muy fragosas y en la estación presente, hombres que no están acostumbrados al frío serian destruidos por sí mismos; por consiguiente, estos puntos quedan defendidos por una invasión por solo su temperamento. El de Cáqueza se halla muy distante, tiene pasos demasiado estrechos por donde corren grandes quebradas, y es muy fácil utilizarlo al pronto, quedando cubierto. ${ }^{5}$

\footnotetext{
${ }^{3}$ Del escrito de Olympo Morales Benítez en 2018 para el libro Ruta Fluvial de la Independencia, investigación recogida por el abogado Pedro Nel Pinzón Guisa.

${ }^{4}$ Dousdebés, Pedro J. Trayectoria militar de Santander. Bucaramanga: Imprenta del Departamento, 1939, p. 164 [cursivas propias].

${ }^{5}$ Tomado de: http://www.bdigital.unal.edu.co/5659/155/cartas_386_a_472_tomo_2.pdf, pp. 162-163.
} 
El ejército que iba a emprender esta formidable escalada de la cordillera estaba compuesto así: dos mil ciento cuarenta y seis llaneros, ingleses de esta legión y oficiales venezolanos y granadinos que habían llegado comandados por Bolívar, y mil ochocientos combatientes dirigidos por Santander que era el ejército de la Nueva Granada y que, atendiendo el encargo de Bolívar, se constituía en la División de Vanguardia comandada por Santander.

Grandes los dos: Santander y Bolívar. Unidos en un propósito grande, la libertad de Indoamérica que acometieron juntos y culminaron, no sin dificultades, pero con éxito. No es concebible la existencia en la historia del uno sin el otro.

\section{Vicepresidencia de Santander}

Su tránsito de la vida militar a la dirigencia civil no tuvo solución de continuidad. El general Francisco de Paula Santander acompaña al libertador en la exigente tarea de diseñar una forma democrática y republicana, que enmarcara jurídicamente el territorio liberado y a él encomendado, y se convierte en el "Arquitecto de la Nación" en el mismo año de la Batalla de Boyacá (1819), al ser ungido como vicepresidente de la Nueva Granada.

Lo esperaban labores administrativas muy exigentes, y tuvo el buen juicio de escoger una serie de varones ilustres para que lo acompañaran en la tarea de consolidar una democracia apenas soñada y una forma de estado aún incipiente en su concepción por los enciclopedistas franceses y los firmantes del Acta de Independencia de los trece Estados Unidos de América (1776).

\section{Hacia lo consolidación de la emancipación}

Santander como vicepresidente (1819-1821), se concentra en la consolidación del sueño libertario desde el gobierno. Se hace acompañar de un gabinete de guerra para lograr la consolidación de la libertad. Escoge a Alejandro Osorio Uribe como su Secretario de Hacienda y Guerra. El nombre mismo de la cartera, Hacienda y Guerra, nos señala que la tarea de Santander y Bolívar de consolidar en Indoamérica la libertad por medio de la conducción de los ejércitos estaba aún lejos de haber terminado. Vicente Azuero Plata será nominado Asesor de Hacienda y Auditor de Guerra, intentando garantizar así la pulcritud en el uso de los recursos que demandaba la búsqueda de la libertad continental. Luis Eduardo Azuela, como Intendente General de Rentas, acepta la pesada carga de recaudar los recursos, tarea siempre ingrata. José Miguel Pey, Superintendente de la Casa de la Moneda, iniciará la consolidación de lograr que el circulante mantenga su valor de intercambio sin oscilaciones exageradas. Pedro Gual, como Secretario de Relaciones Exteriores, debe lograr el reconocimiento de incipientes naciones. Pedro Briceño Méndez, Carlos Soublette y Lino Clemente serán, cada uno en su momento, secretarios de Guerra y Marina y deberán impedir que toque tierra cualquier enemigo (español, inglés, francés y/o holandés) del ambicioso proyecto libertario y democrático.

\section{Santander intenta, desde la educación, consolidar la ruta hacia la consolidación de la emancipación}

Santander, fundador civil de la República, dedicó su vida por completo a defender la integridad, la estructura y el sistema democrático. Gracias a esto, Colombia es un icono y baluarte de los principios democráticos en Indoamérica. Considera que la instrucción es el inicio del camino. El consagrado investigador y reverenciado historiador Luis Horacio López Domínguez nos apoya en esta afirmación:

Entre 1819 y 1821, por decreto, Santander y Bolívar van avanzando en el dominio de la instrucción pública [...]. Las leyes de instrucción pública expedidas por el Congreso de 1821 dieron fundamento a las medidas de Santander. ${ }^{6}$

\footnotetext{
${ }^{6}$ López-Domínguez, Luis Horacio. Obra educativa de Santander 1819 -1826. Bogotá: Fundación
} Francisco de Paula Santander, 1990. 
No se detendría la vorágine educativa que posee a Santander. Introduce el método lancasteriano. Funda escuelas en Mariquita, Honda y Valledupar (1822). Funda los colegios de San Simón y Boyacá. Normales lancasterianos en Bogotá, Caracas y Quito. Dirige la Gaceta de Colombia, periódico oficial. Entre 1822 y 1825 funda 125 Colegios. En 1826 es reelegido para el siguiente periodo. Dicta el decreto de enseñanza pública y funda la Academia Nacional para fomentar las artes, las letras, la política y la moral, y en 1827 establece la Universidad de Boyacá. En 1932 es nombrado presidente y ejerce la primera magistratura.

\section{El gobernante}

Tal y como lo refirió la historiadora Pilar Moreno de Ángel, Santander:

Ejerció la primera magistratura de la república del 1 de abril de 1833 al 1 de abril de 1837 . A las 6:32 del 6 de mayo de 1840 murió el general Francisco de Paula Santander. Las palabras finales del estadista fueron: “¡Ahora sí! ¡Adiós, mis amados amigos!”. Se extinguía así la vida de uno de los más notables ciudadanos de América, a quien le había correspondido por fuerza del destino desempeñarse como militar, jurista, estadista y esencialmente como el fundador civil de la república. ${ }^{7}$

Por las calendas en que se rinde este merecido homenaje a Francisco de Paula Santander en la Academia de Ciencias Exactas, Físicas y Naturales, también se conmemora en toda Colombia el centenario del natalicio del pensador provinciano, el humanista y combatiente permanente por la construcción de la paz y la preservación de la democracia. Otto Morales Benítez, de quien quiero recordar la magistral síntesis que hizo de lo que significó el pensamiento siempre vigente y oportuno de Santander, dijo:

La cercanía a la figura de Francisco de Paula Santander sirve para reclamar la fidelidad a las instituciones republicanas, para reiterar nuestra vocación civilista. Para insistir en la majestad y la necesidad del congreso. También para declarar que confiamos más en los errores colectivos de la democracia que en los poderes absolutistas. Que no nos entusiasma el providencialismo y estamos lejos de aceptar que las armas sean el único derrotero político para alinear nuestro ánimo arisco y tropical.

Se quiere decir, en síntesis, que pensamos más en la educación que en la represión y que amamos la ley sin delirio demagógico, pero sin dudar de que ésta lentamente ordena la conducta humana. Por todo ello nos podemos congregar al pie de las ideas del general Francisco de Paula Santander de sus enseñanzas de sus tesis que permanentemente van caminando hacia la claridad social, hacia el resplandor colectivo, haciendo de cada uno de estos principios conducta y destino de los hombres hacia el quehacer republicano para señalar el derrotero de la patria. ${ }^{8}$

Francisco de Paula Santander, insuperable como militar y cómo hombre público, convocó una pléyade de grandes repúblicos que fraguaron con el combatiente en lo cívico y en lo militar los cimientos de nuestra hoy sólida y grande nación colombiana a la cual nos hemos sentido siempre orgullosos de pertenecer e intentar servir desde las actividades educativas, jurídicas, políticas, empresariales y familiares que nos empeñamos en alentar y honrar para que desde nuestro anónimo y modesto ejercicio ciudadano, sirvan de ejemplo a las generaciones por venir que quieran preservar el estado de derecho, los regímenes de libertad, de construcción de paz y de adecuadas conductas personales.

\section{Olympo Morales Benítez}

Presidente

Academia Santanderista de Colombia

Bogotá, Torres del Este, 2020

\footnotetext{
${ }^{7}$ Moreno de Ángel, Pilar (2019). Santander. Bogotá: Planeta Colombiana S. A.

${ }^{8}$ Morales Benítez, Otto, citado en: Galindo, Julio Roberto. El liberalismo en la historia. Bogotá: Universidad Libre, 2017.
} 